\title{
RELATING ERP CONFIGURATION MODELS TO STRATEGY OF ORGANIZATIONS
}

\author{
Adhir Tandon ${ }^{1}$, N.Roy ${ }^{2}$ \\ ${ }^{l}$ Department of Mechanical Engineering, Motilal Nehru National Institute of Technology, Allahabad \\ ${ }^{2}$ Department of Mechanical Engineering, Motilal Nehru National Institute of Technology, Allahabad
}

\begin{abstract}
Two Competing methods of ERP configuration are reported in the literature: OOM (Object Oriented Methodology) and DEM (Dynamic Enterprise modeling). OOM is comparatively cheap, simple and fast, whereas DEM allows for handling uncertainty in businesses. We argue that choice of ERP Configuration varies with the organizational strategy types. For defenders type of organizations OOM method for configuring ERP will be most suitable and for prospectors and analyzers (that have higher business uncertainty) DEM method for ERP configuration will be most suitable.
\end{abstract}

Keywords: ERP, ERP Configuration models, Business Strategies

$* * *$

\section{INTRODUCTION}

Enterprise Resource Planning (ERP) is business management software used for storing and managing data from almost every stage of business, including: Product planning, cost and development; Purchase and supplier relationship management (SRM); Manufacturing; Marketing and sales; Inventory management; Shipping and payment; and Customer relationship management (CRM) (wikipedia.org). It provides an integrated real-time view of these core business processes, using common databases maintained by a database management system. Organizations consider the ERP system a vital organizational tool for success because it integrates varied organizational systems and facilitates error-free transactions and production (Shaul and Tauber, 2012). Benefits derived from ERP system varies with organization, modules deployed and success of ERP implementation. Most ERP systems incorporate best practices- reflecting the vendor's interpretation of the most effective way to perform each business process. Systems vary in how conveniently the customer can modify these practices (Monk and Wagner, 2009). One of the key reasons of adopting ERP systems offered as-it-is is that upgrading customized ERP systems is laborious and costly and customizations have to be re-coded every time ERP systems are upgraded (Haines, 2009).

Though there are many benefits that can be reaped through ERP implementation, it is important that these benefits should outweigh the high costs of the system and this is possible as long as the correct ERP system for the organization is chosen and implemented properly. Analyst firm Gartner estimates that $55 \%$ to $75 \%$ of all ERP projects fail to meet their objectives and there are many lessons to be learned from these failed ERP implementations. Wong, Ada, et al (Wong, 2005) in their study on critical failure factors in ERP implementation identified three common factors across all case studies viz- poor consultant effectiveness, poor project management effectiveness and poor quality of businessprocess re-engineering. Another important reason identified behind these failures was ERP system misfit with the organization practices itself.Therefore to be successful, it is imperative that either ERP system deployed should match the needs of business or business should align with the ERP requirements. Our research pertains to the choice of ERP technology in relation to organization strategy (structure and processes).

\section{THEORETICAL FRAMEWORK}

In the face of an increasingly turbulent business and technology environment, the keys to success of information technology driven organization lie in its ability to be adaptive, responsive, and aligning Information system (IS) to business needs (Ross et al., 1996). Researchers in the area of IS have responded by examining the necessity and benefits of aligning IS with the rest of the business (Camillus and Lederer, 1985; Chan et al., 1997; King and Teo, 1997; Qing and Huang, 2005; Chan et al., 2007). Most of the researchers worked on the definition of customization of ERP as per organization's requirements and on effects of implementation of best practices on the organization. But empirical research on the choice of ERP models in relation to strategy has not been dealt adequately; which we attempt to study in this work. The strategic orientations of organization are taken from seminal work of Miles and Snow strategic framework typologies (Miles et al., 1978).

Miles et al. developed a general model of the organization's adaptive process based on organization's strategy that further gives shape to its structure and processes. On the basis of strategies employed, in solving their entrepreneurial, engineering, and administrative problems, they have defined four organizational strategy types: defender, prospector, analyzer and reactor. Each type of organization follows unique strategy for its own market and adopt particular configuration of technology, structure and process. 
Defenders: Defenders are organizations that deal with narrow and stable product domain and try to maintain their position by offering better quality and lower cost products. They have cautious and incremental growth primarily through market penetration. They try to develop single core technology related with current goods or services and are often vertically integrated. They maintain centralized and formalized administrative system to ensure compliance with the laid efficient path.

Prospectors: are opposite of defender, dwelling in broad and continuously evolving market domain; often they are the creators of change in the market by their novel offerings. As their market domain is always in transition they make use of multiple technologies for production and distribution of good. Their organization structure is organic and flat following a few permanent processes and more flexible attributes.

Analyzers: Analyzer is unique combination of defender and prospector, dwelling in hybrid domain that is both stable and changing. In their stable domain they have structure and processes like defender and in emerging product domain have flexible/adoptive system. They keep surveillance on market developments and have some research and development to adopt and respond. So they have both steady growth through market penetration and product-market development.

The fourth type described as Reactor organizations, which do not have a systematic strategy, design, or structure and are not proactive for changes in their business environments. They respond only when market forces them to do so. We have not considered them due to their irrelevance in current competitive environment.

Sabherwal and Chan (2001) studied the alignment process between these businesses strategies and Information System (IS) strategies. According to them, for prospectors the alignment between IS strategy and the IS for flexibility strategy is positively associated with perceived business performance. While for analyzers the alignment between IS strategy and the IS for comprehensiveness strategy is positively associated with business strategy. They conclude that alignment between IS strategy and business strategy improves business performance.

\subsection{Configuration Models for ERP: OOM \& DEM}

Among the existing ERP systems, the two most prevalent types of systems are: Object oriented methodology (OOM) also termed as traditional ERP and Dynamic enterprise modeling (DEM). Both have their own unique set of pros and cons. A brief introduction is given below (Soffer et al., 2005).

i. Object oriented methodology: Object-oriented methodology works on object oriented principle of software development. It permits multiple implementations of objects to coexist while protecting clients from changes in implementation or representation by hiding data representation and implementation details behind objectoriented interfaces. Therefore the evolution part of the software is only partially addressed. It needs more customization and vendor support if the requirements are unstable and constantly changing because accommodating such changes entail changes in the way the objects are structured and configured.

\section{ii. Component-Tailoring: Component tailoring} methodology is an extension of object oriented methodology, with notion of component as more general than that of an object. An object encapsulates data and its associated behavior, whereas a component may encapsulate any useful software. Component -tailoring methodology views each application as only one instance of a generic class of applications, each built up of reconfigurable software components. Components provide a plug and play implementation system, thus increasing more flexibility to the ERP system configuration and implementation compared to object oriented methodology.

DEM is an enterprise modeling technique based on component tailoring methodology employing one enterprise structural model, several business models, one enterprise data model and other component based models. It provides a framework for enterprises to closely match business processes, functions and so on, which get changed frequently.

\subsection{Hypothesis Building}

As stated earlier with reference to past research paper findings, organizations choose Information systems based on their organization strategy. As defender type of organization has more centralization, standardization, formalization and less complexity and flexibility, it will go for traditional Information system methodologies like OOM. Prospector and analyzer instead would go for DEM based ERP which can generate critical real time information for flexible decision making and can provide last minute changes in configuration without much customization. Based on above theoretical literature and our assumption we formulate the hypothesis as:

Hypothesis 1: Defender type of organization will opt for object-oriented methodology for ERP configuration.

Hypothesis 2: Prospectors and analyzers type of organization will opt for Dynamic enterprise modeling for ERP configuration.

\section{RESEARCH METHODOLOGY}

In our preliminary study, we studied the ERP implementation methodologies in few organizations; choosing them from different industry sector. For studying the suitability of the ERP implementation methodologies we collected responses from their ERP consultants. These consultants are totally aware with the organization's business strategy attributes and ERP implementation methodologies used in that organization. We also collected responses from the managers of these organizations to avoid bias results. In this study we used the questionnaire with 
objective and short response. Questionnaire was designed for assessing the business strategy of organization (Chatterjee et al., 2005) and also enquired about the choice of implementation methodology in use. The sample comprised of 9 companies. These companies operate in different business domains like Packaging, FMCG, Pharmaceuticals, Automotive, Food processing. Following are the brief profile about these companies. Their names have been indexed as promised in survey.

Company A: is a provider of cleaning and hygiene products to the institutional marketplace, serving lodging, food service, retail, health care, food and beverage companies, as well as building service contractors worldwide.

Company B: is a globally recognized MNC and operates in different business domains like healthcare, pharmaceuticals, Equipment, etc.

Company C: is a globally recognized Swedish MNC manufacturing personal and household appliance.

Company D: is a global satellite services provider and developer of hybrid video delivery technologies.

Company E: is world's second largest pharmaceutical company manufacturing medical drugs and vaccines.

Company F: is world leader in soft beverages and also manufactures other food products.

Company G: is a consumer goods company with interests in Hair Care, Oral Care, Health Care, Skin Care, Home Care and Foods.

Company H: is a leading supplier of Axles, Driveshaft (also known as Propeller shafts), and Drive train products.

Company I: is India's market leader in the supply of rice processing systems, flour mills, color sorters and feed manufacturing plants.

We analyzed the collected data to confirm the earlier framed hypothesis for ERP implementation.

\section{DATA ANALYSIS}

Since the sample size is small not much statistical analysis was deployed. Using the software SPSS (Statistical Package for the Social Sciences) Cranach's alpha was found, which was above 0.6 , ensuring the reliability and consistency of the survey response. Questions were so constructed that higher score in each case will position the firm as defenders and lower scores as prospectors. The classification of firms into defenders (D), prospectors (P), analyzers (A) was based on rationale that higher score in structural attribute will mean the firm is a defender and lower scores as prospector characteristic. Companies showing medium scores in structural attributes were classified as analyzers. It has been argued (Miles and Snow, 1978) that Defenders (low cost leaders) are likely to have high scores on organization dimensions--standardization, specialization, centralization and formalization and low scores on complexity of workflow, where as Prospectors are likely to have low scores on standardization, specialization, centralization and formalization and high scores on complexity of workflow. In this work, the average score on Standardization, Specialization, Centralization, and Formalization $\geq 3$ classified organizations as Defender; and if the average score on these dimensions was $\leq 2$ then the organization is classified as Prospector. Table 4 shows classification of these companies and their choice of ERP based on sample responses.

Table 4: Strategic Classification of Companies

\begin{tabular}{|l|l|l|}
\hline Company & $\begin{array}{l}\text { Organization } \\
\text { type }\end{array}$ & ERP methodology \\
\hline A & Analyzer & Other \\
\hline B & Analyzer & DEM or custom tailoring \\
\hline C & Analyzer & DEM or custom tailoring \\
\hline D & Analyzer & DEM or custom tailoring \\
\hline E & Prospector & DEM or custom tailoring \\
\hline F & Analyzer & DEM or custom tailoring \\
\hline G & Prospector & DEM or custom tailoring \\
\hline H & Defender & Object oriented methodology \\
\hline I & Defender & DEM or custom tailoring \\
\hline
\end{tabular}

\section{RESULTS AND DISCUSSION}

Looking at Table 4 we see almost all prospectors and analyzers companies opted for DEM ERP verifying Hypothesis2. As far as defender companies are concerned responses show equal preference for the two configurations. The sample being small can be the reason of not proving or discarding Hypothesis1. We are planning to conduct a largescale study to confirm these hypotheses.

In this work, we tried to link the properties of ERP configuration methodologies to the structural attributes of organization's business strategy proposed by Miles and Snow. Based on the preliminary sample responses, our hypotheses that the defenders go for traditional ERP methodologies like object oriented whereas prospectors and analyzers will go for modern methodologies such as DEM, seem fulfilling. But for statistical justification more samples are required.

The bias in favor of DEM choice of ERP implementation can be attributed to the recent changes in market trends and increase in competition due to globalization. In the current scenario the changes in markets are rapid and overall competition has become very intensive. Traditional ERP systems (OOM), which undergo user-defined customization by vendor to meet organization's specific market and operational needs, don't solve the problem of high cost and delivery time. Most ERP implementation methodologies in demand are those based on component and reconfiguration technologies. BANN has proposed the concept of dynamic enterprise modeling (DEM), and SAP uses the technology of component tailoring based on the enterprise model. Both help improve the flexibility of systems. These ERP systems provide rapid implementation and flexible customization, thereby helping the companies to adapt their business processes to frequent market and demand changes without much customization. Trend is that standardization and flexibility has increased and centralization has gone down in most of the companies, which have used either DEM or custom tailoring methodologies. 


\section{REFERENCES}

[1] Camillus, J.C. and A.L. Lederer., "Corporate Strategy and the development of computerized information systems", Sloan Management REV, Volume 26, Number 3, Pages 35-42, 1985.

[2] Chan, Y.E., D.G. Copeland, and D.W. Barclay, "Business Strategy, information systems strategy, and strategic alignment." Inform. Systems Res., Volume 8, Number 2, Pages 125-150, 1997

[3] Chan, Yolande E., and Blaize Horner Reich. "IT alignment: what have we learned?" Journal of Information technology, Volume 22, Number 4, Pages 297-315, 2007.

[4] Chatterjee, Devjani, Sharma, RRK and Shanker, K., "Important differences in management control systems, cultural dimensions and management practices of innovators, prospectors and defenders", 3rd European Conference on Entrepreneurship and Innovation, The University of Winchester, UK, 15-16 Sept, 2008

[5] Haines, M., "Understanding enterprise system customization: An exploration of implementation realities and the key influence factors". Information Systems Management, Volume 26, Number 2, Pages 182-198, 2009.

[6] http://en.wikipedia.org/wiki/Enterprise_resource_pla nning

[7] King, W.R., T.S.H. Teo. , "Integration between business planning and information systems planning: Validating a stage hypothesis". Decision Science, Volume 28, Number 2, Pages 279-308, 1997.

[8] Miles, Raymond E., et al., "Organizational strategy, structure, and process." Academy of management review, Volume 3, Number 3, Pages 546-562, 1978.

[9] Monk, Ellen and Wagner, Brett.,Concepts in Enterprise Resource Planning. 3rd.ed.Course Technology, Cengage Learning. Boston, Massachusetts, 2009.

[10] Qing Hu; Huang, C.D., "Aligning IT with Firm Business Strategies Using the Balance Scorecard System," System Sciences, 2005. HICSS '05. Proceedings of the 38th Annual Hawaii International Conference on System Sciences, IEEE, Page 230a, Jan. 2005.

[11] Ross, J. W., Beath, C. M., and Goodhue, D. L., "Building Long-term Competitiveness Through IT Assets", Sloan Management Review, Volume 38, Number 1, Pages 31-42, Fall 1996.

[12] Sabherwal, R. and Y. E. Chan., "Alignment between Business and IS Strategies: A Study of Prospectors, Analyzers, and Defenders." Information Systems Research, Volume 12, Number 1, Pages 11- 33, 2001.

[13] Shaul, L. and Tauber, D., "CSFs along ERP lifecycle in SMEs: a field study", Industrial Management \& Data Systems, Volume 112, Number 3, Pages 360-384, 2012.

[14] Soffer, Pnina, Boaz Golany, and DovDori, "Aligning an ERP system with enterprise requirements: An object-process based approach." Computers in
Industry, Volume 56, Number 6, Pages 639-662, 2005.

[15] Wong, Ada, Harry Scarbrough, Patrick Chau, and Robert M. Davison. "Critical Failure Factors in ERP Implementation." In PACIS, Page 40, 2005.

\section{BIOGRAPHIES}

AdhirTandon, is a PhD scholar at Department of Mechanical Engineering, Motilal Nehru National Institute of Technology, Allahabad

N.Roy is Professor, Department of Mechanical Engineering, Motilal Nehru National Institute of Technology, Allahabad 